\title{
Observed Water- and Light-Limitation Across Global Ecosystems
}

5

\author{
François Jonard ${ }^{1,2}$, Andrew F. Feldman ${ }^{3,4}$, Dan J. Short Gianotti ${ }^{5}$, Dara Entekhabi ${ }^{5}$
}

${ }^{1}$ Earth Observation and Ecosystem Modelling lab, SPHERES research unit, Université de Liège (ULiege), Allée du Six Août 19, 4000 Liège, Belgium

${ }^{2}$ Agrosphere (IBG-3), Institute of Bio- and Geosciences, Forschungszentrum Jülich GmbH, Germany

${ }^{3}$ NASA Postdoctoral Program, NASA Goddard Space Flight Center, Greenbelt, MD, USA

$10{ }^{4}$ Biospheric Sciences Laboratory, NASA Goddard Space Flight Center, Greenbelt, MD, USA

${ }^{5}$ Parsons Laboratory, Department of Civil and Environmental Engineering, Massachusetts Institute of Technology (MIT), Cambridge, MA, USA

Correspondence to: François Jonard (francois.jonard@uliege.be)

15

Abstract. With a changing climate, it is becoming increasingly critical to understand vegetation responses to limiting environmental factors. Here, we investigate the spatial and temporal patterns of light and water limitation on photosynthesis using an observational framework. Our study is unique in characterizing the nonlinear relationships between photosynthesis and water and light, acknowledging approximately two regime behavior (no limitation and varying degree of limitation). It is also unique in using an observational framework instead of using model-derived photosynthesis properties. We combine data from three different satellite sensors, i.e., solar-induced chlorophyll fluorescence (SIF) from TROPOMI, surface soil moisture from SMAP, and above-ground canopy density from MODIS. We find both single-regime and two-regime models describe SIF sensitivity to soil moisture and photosynthetically active radiation (PAR) across the globe. The distribution and strength of soil moisture limitation on

SIF are mapped in the water-limited environments while distribution and strength of PAR limitations are mapped in the energy-limited environments. Two-regime behavior is detected in $73 \%$ of the cases for water limitation on photosynthesis, while two-regime detection is much lower at $36 \%$ for light limitation on photosynthesis. SIF sensitivity to PAR strongly increases along moisture gradients, reflecting mesic vegetation's adaptation to making rapid usage of incoming light availability on the weekly timescales. The transition point detected between the two regimes is connected to soil type and mean annual precipitation for the SIF-soil moisture relationship and for the SIF-PAR relationship. These thresholds have therefore an explicit relation to properties of the landscape, although they may also be related to finer details of the vegetation and soil interactions not resolved by the spatial scales here. The simple functions and thresholds are emergent behaviors capturing the interaction of many processes. The observational 
thresholds and strength of coupling can be used as benchmark information for land surface and Earth system models,

\section{Introduction}

Vegetation plays a large role in the Earth system, modulating land-atmosphere exchanges of water, carbon, and energy (Beer et al., 2010; Jasechko et al., 2013). With increasing temperatures and possibly more intense drought and heatwaves, factors affecting vegetation productivity have impacts on global carbon budgets and food security (Gentine et al., 2019; Huang et al., 2018; Liang et al., 2017). It is therefore imperative to understand how vegetation function responds to environmental and rate-limiting factors across the globe. More specifically, it is important to understand how climatic factors create limitations on vegetation function at large spatial scales (Ahlström et al., 2015; Zhang et al., 2020a,b). Such determinations using observed datasets are key for predicting and validating terrestrial ecosystem productivity responses in Earth system models (Fisher et al., 2018), ultimately improving our ability to predict the future land surface conditions in the context of global change.

Remote sensing has proven to be a useful tool for mapping and monitoring vegetation function across the globe. Satellite observations provide the ability to spatially-integrate over the behavior of whole ecosystems, providing scaled up behavior relevant to the global carbon cycle and Earth system models. Observations of sun-induced chlorophyll fluorescence (or commonly called solar-induced fluorescence; SIF) — radiation emitted at wavelengths of 650 to 800 $\mathrm{nm}$ from plant photosystems - are valuable indicators of ecosystem photosynthetic activity. In contrast to traditional vegetation reflectance indices, SIF is sensitive to diurnal and seasonal photosynthetic dynamics and not only to changes in greenness (Wang et al., 2020). SIF emission is connected to transpiration and photosynthesis related processes and these relationships are controlled by intrinsic water use efficiency (WUE) and light use efficiency (LUE). Recent studies have shown the value of satellite observations of SIF to monitor ecosystem transpiration (Lu et al. 2018; Shan et al., 2019; Pagan et al., 2019; Maes et al., 2020) and productivity (gross primary production, GPP) (Joiner et al., 2014; Zhang et al., 2016; He et al., 2020). Since 2009, surface soil moisture (SM) can also be derived globally from low microwave frequency radiometer observations (Kerr et al., 2010; Entekhabi et al., 2010). While microwave measurements are sensitive to the water in the top 5-10 centimeters of the soil profile, it has been shown that SM estimates averaged over several days are both physically and statistically correlated to deeper root zone soil moisture 
Using these satellite remote sensing developments, several studies have analyzed the influence of bio-climatic factors on productivity. Madani et al. (2017) found that reanalysis-derived soil moisture (SM), vapor pressure deficit (VPD), and minimum daily air temperature are significant control factors influencing ecosystem productivity over the globe. They showed that SIF was positively correlated with soil moisture on monthly time-scales in dry biomes (e.g., Sahel), whereas in humid biomes (e.g., Amazonia), SIF was negatively correlated with soil moisture and positively correlated to VPD. While Global Ozone Monitoring Experiment-2 (GOME-2) satellite SIF observations were used as proxy of productivity, environmental factors were derived from model reanalysis data, which may have model-prescribed relationships between one another and with productivity. In addition, factors influencing vegetation growth were limited to temperature and moisture constraints, but other environmental controls such as light limitation were not addressed.

Similarly, Nemani et al. (2003) have analyzed the impact of global climate changes on vegetation productivity using global reanalysis data and a production efficiency model. Their results indicate mainly a reduction of climatic constraints to plant growth during the last two decades of the past century, with significant increase in net primary production over large regions of Earth such as in Amazon rain forests. Walker et al. (2020) review theory and evidence suggesting a substantial increase in global photosynthesis since pre-industrial times driven at least in part by increased atmospheric carbon dioxide concentration leading to increases in plant water use efficiency.

Recently, using Orbiting Carbon Observatory-2 (OCO-2) SIF and Soil Moisture Active and Passive (SMAP) SM satellite observations, Gonsamo et al. (2019) found that SM was often a primary limiting factor to plant growth in drylands and croplands. While based on a low number of concurrent SIF and SM data records, the authors observed positive and stronger SIF-SM relationships in drier and warmer regions. In their study, nonlinear behaviors were not addressed.

Using satellite observations of SIF and climate data sets, Liu et al. (2020) found that SM has a dominant role in determining dryness stress on ecosystem production over most land vegetated areas. However, the study was primarily interested in moisture effects, having investigated the relative role of SM and VPD in limiting ecosystem production. Short Gianotti et al. (2019a) showed that SIF-SM relationships match satellite-derived GPP-SM relationships in both time and space, with little-to-no SIF-SM relationship in the light-limited humid regions of the contiguous United States and increasing response strength with aridity. Water-limited regions showed strong increases in ecosystem-water use efficiency (daily SIF or GPP divided by latent heat flux) during SM dry spells. 
https://doi.org/10.5194/bg-2022-25

Preprint. Discussion started: 31 January 2022

(c) Author(s) 2022. CC BY 4.0 License.

Studies investigating global drivers of photosynthesis tend to focus on linear relationships between these variables,

Gianotti et al., 2019a; Bassiouni et al., 2020). Those that evaluate nonlinear relationships do so regionally or globally

light across climates and biomes remains under-characterized.

The objective of this study is to evaluate the environmental factors that limit surface water and carbon exchanges over vegetated areas. Specifically, we ask: what are the conditions under which SIF is limited by water and light in space and time? Can we detect first-order nonlinear controls of water and light on photosynthesis as suggested from theory? If so, are there climatic controls on the water and light availability thresholds that divide regimes of SIF nonlinear responses to environmental variables? Here, we use an observation-based framework to evaluate nonlinear relationships between SIF and available water and light. Observations are key to provide benchmark information for parameterizing effects of water-stress or light-limitation on ecosystem productivity in Earth system models. Modeled vegetation products can implicitly or explicitly parameterize the relationships between SIF and water and light that we intend to evaluate. In this observationally driven study, we combine three data streams — sun-induced chlorophyll fluorescence (SIF) from TROPOMI, surface soil moisture from SMAP, and leaf area index (LAI) from MODIS- to globally monitor observational evidence for seasonal water-limitation and light-limitation in plant function.

\section{Data}

Satellite-based data were collected for a 2.5-year period from April 2018 to September 2020 (determined by the concurrently available TROPOMI and SMAP data).

\subsection{Global Satellite Data}

\subsubsection{TROPOMI Solar-Induced Fluorescence}

Sun-induced chlorophyll fluorescence (SIF, $\mathrm{mW} \mathrm{m}^{-2} \mathrm{~nm}^{-1} \mathrm{sr}^{-1}$ ) data are obtained from the TROPOspheric Monitoring Instrument (TROPOMI) aboard the Sentinel-5 Precursor (Köhler et al., 2018). TROPOMI provides optical observations with a spectral resolution of $0.5 \mathrm{~nm}$, a spatial resolution of $7 \times 3.5 \mathrm{~km}^{2}$ (along track $\mathrm{x}$ across track) at 
https://doi.org/10.5194/bg-2022-25

Preprint. Discussion started: 31 January 2022

(c) Author(s) 2022. CC BY 4.0 License.

nadir, and almost global coverage within 1 days. Sentinel -5 Precursor has an overpass time near 13:30 local solar time. SIF is retrieved in a spectral window ranging from 743 to $758 \mathrm{~nm}$ using the method of Köhler et al. (2018). Zero values (non-vegetated areas) were filtered out.

\subsubsection{SMAP Soil Moisture}

Surface soil moisture $\left(\mathrm{SM}, \mathrm{cm}^{3} \mathrm{~cm}^{-3}\right)$ data (top $5 \mathrm{~cm}$ ) are from the L-band $(1.4 \mathrm{GHz})$ microwave radiometer aboard the NASA Soil Moisture Active/Passive (SMAP) satellite (Entekhabi et al., 2010). Microwave observations from the 6 a.m. descending overpasses were used with a spatial resolution of $36 \times 36 \mathrm{~km}^{2}$ and a global coverage within 3 days. Retrievals of soil moisture were obtained using the multi-temporal dual channel algorithm (MT-DCA) (Feldman et al., 2021; Konings et al., 2016). The MT-DCA algorithm estimates vegetation attenuation and scattering from an algorithm with temporal regularization. It does not use any information on land-use and ecosystem classifications which would bias the results otherwise. While the microwave measurements are commonly known to reflect the top $5 \mathrm{~cm}$, several lines of evidence suggest SM can viably represent relevant root zone dynamics in most cases. First, under wetter conditions, SMAP SM is known to closely correlate with rootzone dynamics, especially in the upper $50 \mathrm{~cm}$ (Short Gianotti et al., 2019b; Akbar et al., 2018b). Under drier conditions, microwave emission depth originates from deeper than $5 \mathrm{~cm}$, down to a meter in some cases depending on soil properties (Njoku and Entekhabi 1996). Furthermore, many plants, especially species in semi-arid grasslands where we mainly evaluate SIF-SM, have rooting distributions skewed to the upper layers $(<30 \mathrm{~cm})$ with preferential uptake of water in the upper soil layers (Flanagan et al., 1992; Meinzer et al., 1999; Miguez-Macho and Fan, 2021).

\subsubsection{MODIS Leaf Area Index}

Leaf area index $\left(\mathrm{LAI}, \mathrm{m}^{2} \mathrm{~m}^{-2}\right.$ ) data come from the Moderate Resolution Imaging Spectroradiometer (MODIS) aboard the NASA Terra satellite. Retrievals of LAI between April 1, 2015 and September 30, 2019 were obtained from MODIS surface reflectances on an 8 days basis and with a spatial resolution of $500 \mathrm{~m}$ (MCD15A2H LAI product; Myneni et al., 2015).

\subsection{Ancillary Data for Analyses}

Annual mean precipitation are obtained by averaging annual means from NASA's Global Precipitation Measurement (GPM) mission between April 1, 2015 and March 31, 2019 (Huffman et al., 2019). Sand and clay fraction information 
https://doi.org/10.5194/bg-2022-25

Preprint. Discussion started: 31 January 2022

(c) Author(s) 2022. CC BY 4.0 License.

was also obtained (Kim, 2013). These metrics were used to evaluate climate gradients of spatial maps generated in the analysis.

\subsubsection{MERRA-2 Downwelling Photosynthetically Active Radiation}

Daily and downwelling photosynthetically active radiation (PAR, $\mathrm{W} \mathrm{m-2)}$ data are provided by the NASA ModernEra Retrospective analysis for Research and Applications, Version 2 (MERRA-2) global reanalysis (GMAO, 2015). The spatial resolution is $0.5^{\circ} \times 0.625^{\circ}$. While PAR is an observation-driven modelled product, it is not expected to have strong relationships with vegetation function prescribed within the model, but rather be driven mainly by solar seasonality and assimilated atmospheric fields such as cloud cover.

\subsection{Spatial and Temporal Aggregations}

The SIF, PAR and LAI data were regridded on a linear weighting basis to the EASE-2 SMAP grid $\left(36 \times 36 \mathrm{~km}^{2}\right)$. The SIF, SM and PAR data were also aggregated temporally to produce 8-day composites. The temporal aggregation was performed to smooth SIF data, with 8-day aggregation selected to match the exact repeat cycle of SMAP. To increase sample size for the correlation maps and the regime classification, the SIF, SM and PAR data at $36 \times 36 \mathrm{~km}^{2}$ resolution are pooled in $2 \times 2$ pixel boxes, for each 8-day period. In the following section, all maps have therefore a spatial resolution of $72 \times 72 \mathrm{~km}^{2}$.

\section{Methodology}

\subsection{Growing Season Estimation}

Since we analyze the seasonal water-limitation and light-limitation of plant function only during the growing season, the growing season for each global pixel was first defined using LAI climatology. The LAI climatology was developed by averaging four and a half years (April 1, 2015 to September 30, 2019) of LAI data into a mean climatology and smoothing using a 90-day moving average filter (Fig. S1). The growing season was then defined as the six-month period centered on the peak of the LAI climatology. This results in growing seasons centered on DOY between 100 to 275 in the northern hemisphere and DOY typically 0 to 50 and 300 to 365 in the southern hemisphere (Fig. 1). There are a number of different approaches to estimating plant phenology based on satellite measurements (e.g. see Bush et al., 2018; Peano et al., 2019; Morellato et al., 2018; Moulin et al., 1997; Zhang et al., 2006). Ultimately the applied technique depends on the application needs, and the approach followed here is sufficient to characterize the active 


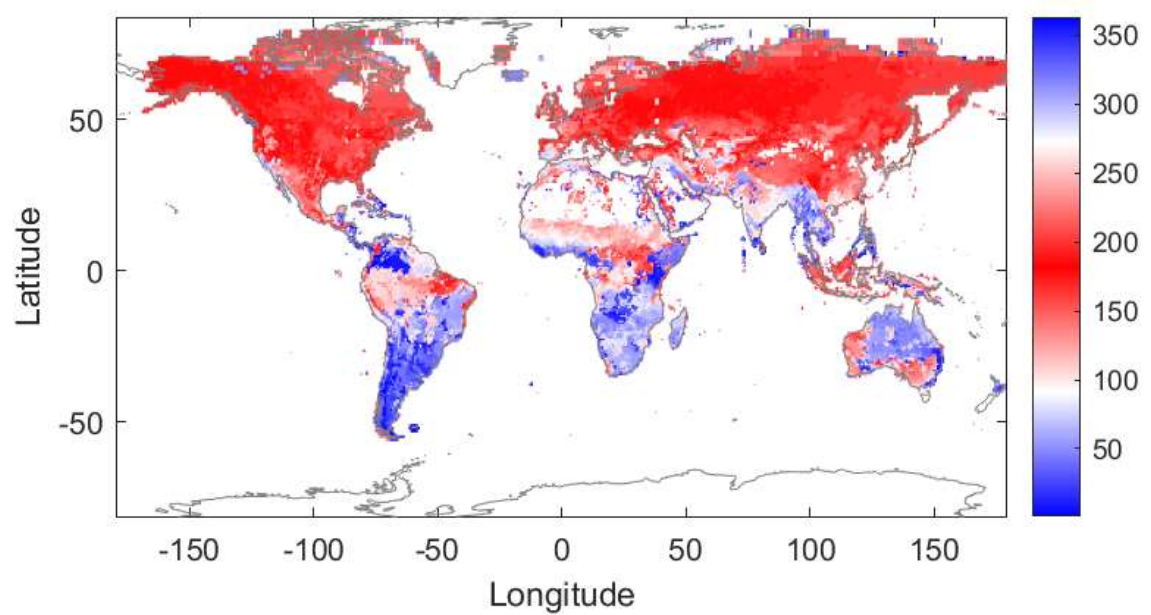

Figure 1: Growing season determination based on satellite leaf area index. Day of the year for the phenological peak based on MODIS LAI climatology. White shading indicates LAI was not available (bare-soil or water bodies).

\subsection{Conceptual Basis}

While chlorophyll fluorescence originates from energy partitioning at the photosystem (leaf) level, at large spatial and temporal scales (as considered in this study), SIF appears as an aggregated landscape variable. It is a function of the absorbed PAR $\left(\mathrm{APAR}_{\mathrm{Chl}}=\mathrm{PAR}\right.$. $\mathrm{PPAR}_{\mathrm{Chl}}$, with $\mathrm{fPAR}_{\mathrm{Chl}}$ being the fraction of PAR absorbed by chlorophyll pigments and mainly controlled by vegetation cover fraction, LAI, leaf chlorophyll content, and plant structure) and the fluorescence quantum yield $\left(\phi_{\mathrm{F}}\right.$, mainly controlled by leaf biochemical properties and is dependent on plant health and water status), both correlated with photosynthetic productivity and strongly influenced by water and energy (light) availability (Joiner et al., 2014; Jonard et al., 2020; Magney et al., 2020):

$\operatorname{SIF}(\lambda)=\operatorname{PAR} \cdot \mathrm{fPAR}_{\mathrm{Chl}} \cdot \phi_{\mathrm{F}}(\lambda) \cdot \mathrm{f}_{\mathrm{esc}}(\lambda) \cdot \tau_{\mathrm{atm}}(\lambda)$

with $\mathrm{f}_{\text {esc }}$ being the fraction of SIF (at wavelength $\lambda$ ) emitted by the chloroplast that leaves the canopy and $\tau_{\text {atm }}$ being the fraction of SIF that also passes through the atmosphere $\left(\tau_{\mathrm{atm}}\right)$.

The behavior of the factors in Eq. (1) differ strongly throughout the globe. For instance, annual croplands tend to show large variations in $\mathrm{PPAR}_{\mathrm{Chl}}$ and $\mathrm{f}_{\text {esc }}$ during the growing season, while these factors are expected to remain more constant 
over evergreen forests. The value of $\phi_{\mathrm{F}}$ is expected to react to the ambient stress conditions. Water- or light limitation comprises the combination of all these components. Light- and water limited photosynthesis will first impact the photosynthetic machinery, affecting $\phi_{\mathrm{F}}$. A prolonged water or light limited regime will manifest in primary production and biomass growth, and therefore on $\mathrm{fPAR}_{\mathrm{Chl}}$ and on $\mathrm{f}_{\mathrm{esc}}$. Evaluating the combination of the parameters in Eq. (1) provides insights on the limiting factors of the plant growth. Futhermore, it is expected that many of these parameters are nonlinearly related to water and light limitation (Xu et al., 2021).

We emphasize that it is not our goal to investigate all possible limiting factors on photosynthesis (e.g., temperature, nutrient limitation), nor how they interact to create states where one or both variables is limiting. A more comprehensive analysis can classify states along multiple axes of climatic factors. Our single axes classification provides a first step towards such classifications in detecting globally where, to a first-order, nonlinear relationships between SIF and water and/or light emerge. It also determines observed spatial variations of the types of climatic factor relationships with SIF. The effects of water and light are at least expected to capture the major global limiting pathways based on previous work (Madani et al. 2017).

\subsection{Correlation Maps}

As a zeroth-order analysis motivating our subsequent evaluation of SIF, we first evaluate the Pearson correlation coefficient between SIF and SM (Fig. 2) and SIF and PAR (Fig. 3) using our 8-day aggregations of each variable. Only values from the growing season are used. In this case, factors that directly limit SIF appear as positively correlated with SIF (in blue in Fig. 2 and 3). Ultimately, the correlation maps guide subsequent analysis of more detailed tworegime behavior. The SIF-SM correlation map (Fig. 2) shows large regions of water limitation (blue regions), such as the Sahel, Eastern and Southern Africa, Eastern Brazil, Southern Asia, and Eastern Australia. The SIF-PAR correlation map (Fig. 3) shows large regions of positive correlation (blue regions), such as much of the United States, Southern Brazil, Europe, and Russia, which are negatively correlated with SM in Fig. 2. Green et al. (2017) provide a more indepth analysis of linear correspondences between vegetation growth and land/atmosphere variables among others. Low SIF-SM correlations occur mainly in densely forested regions where soil moisture estimation uncertainty is largest and potentially surface soil moisture is less of a control on vegetation function than other factors. Regions in blue in Fig. 2 are generally in red in Fig. 3, revealing that SM and PAR are typically negatively correlated (Fig. S2). This is due to synoptic-scale correlations between cloud cover and 1) soil moisture (positive) and 2) shortwave radiation (negative), as well as seasonal-scale alignment of growing-season peaks with peaks in the primarily-limiting 
https://doi.org/10.5194/bg-2022-25

Preprint. Discussion started: 31 January 2022

(C) Author(s) 2022. CC BY 4.0 License.

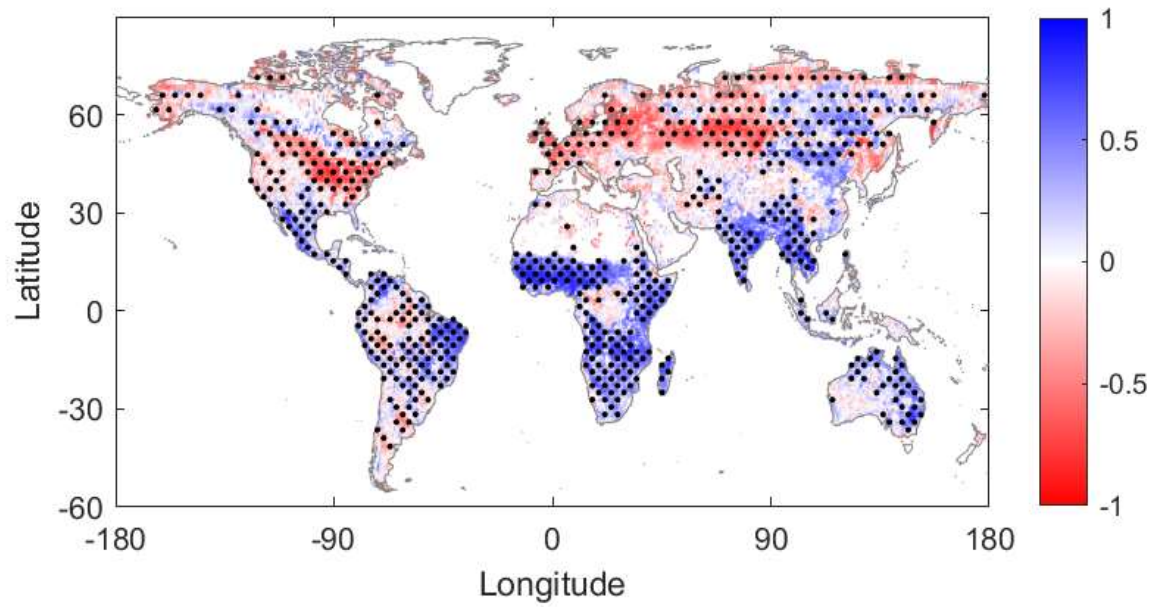

Figure 2: TROPOMI sun-induced chlorophyll fluorescence (SIF) and SMAP MT DCA soil moisture (SM) growing season correlation. Pearson correlation coefficient of 8-day averages. Regions of statistical significance $(P<0.05)$ are indicated with 


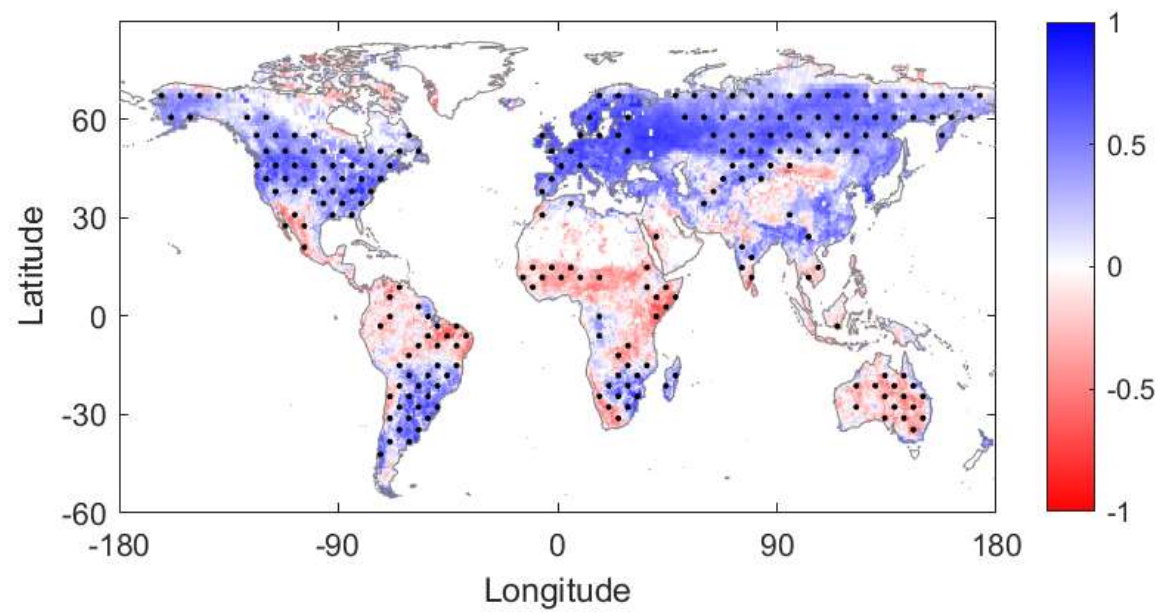

Figure 3: TROPOMI sun-induced chlorophyll fluorescence (SIF) and MERRA-2 photosynthetically active radiation (PAR) growing season correlation. Same conventions as Fig. 2.

\subsection{Regime classification}

Pearson correlation provides information about the degree to which a variable linearly limits SIF. However, in many cases, nonlinear relationships are present where the strength of limitation may decrease above a certain threshold of soil moisture or photosynthetically active radiation (e.g., see Fig. 4). This therefore can bias linear correlations and obscure their interpretation in Figs. 2 and 3 as well as previous studies (Gonsamo et al. 2019). We approximate this relationship here as a two-regime linear model to characterize conditions when water or light limit SIF. In some instances, only one regime may be observed for either water or light. Therefore, three distinct models were tested representing three scenarios for each limitation (water and light) (Fig. 5) as in previous studies that evaluated surface energy fluxes (Akbar et al. 2018a; Feldman et al. 2019).

The following models are used for SM and PAR separately and independently. Only model selections are completed in the pixels where the given variable is positively correlated with SIF (Figs. 2 and 3). If a given pixel shows a positive SIF correlation with both SM and PAR, then models for both SM and PAR are estimated. The first model is the linear model representing the water- or light-limited regime (Fig. 4a and d). Here, the conditions are always characterized by water- or light-limitation without another regime of behavior detected. An increment of SM or PAR always impacts photosynthesis and therefore the SIF. The second model is the full two-regime model representing the two-regimes of 

estimated. Below this threshold, the given variable limits SIF. Above the threshold, an increment of SM or PAR will not affect photosynthesis. The third model is the zero-slope model for the no water or no light limitation regime (Fig. $4 \mathrm{c}$ and $\mathrm{f}$ ). In this case, plant growth is not sensitive to water or light within the variability observed at that location. A model is selected based on the Bayesian Information Criterion (BIC) in order to avoid over-fitting among models shown in Fig. 4. Example pixels are shown in Fig. 5 where the two-regime model model is selected by this method.

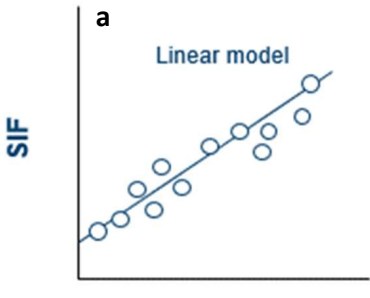

SM

Water-Limited

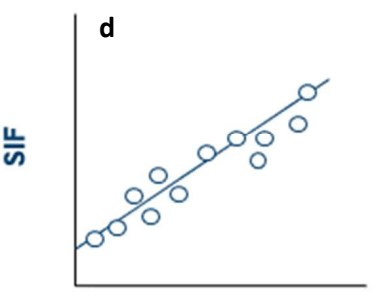

PAR

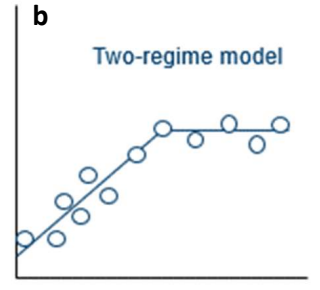

SM

Two-Regime Water-Limited

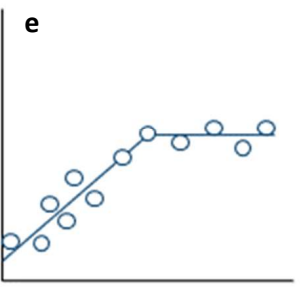

PAR

Two-Regime Light-Limited

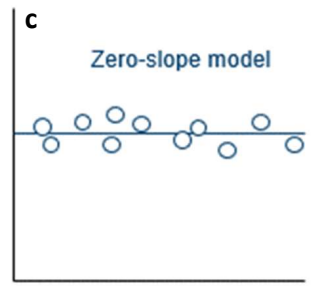

SM

No Water Limitation

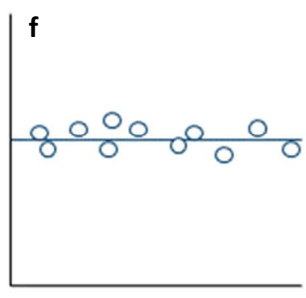

PAR

Figure 4: Schematics of model types for the SIF-SM and SIF-PAR regimes. Bayesian Information Criterion (BIC) is used to avoid over-fitting among models during statistical selection. 

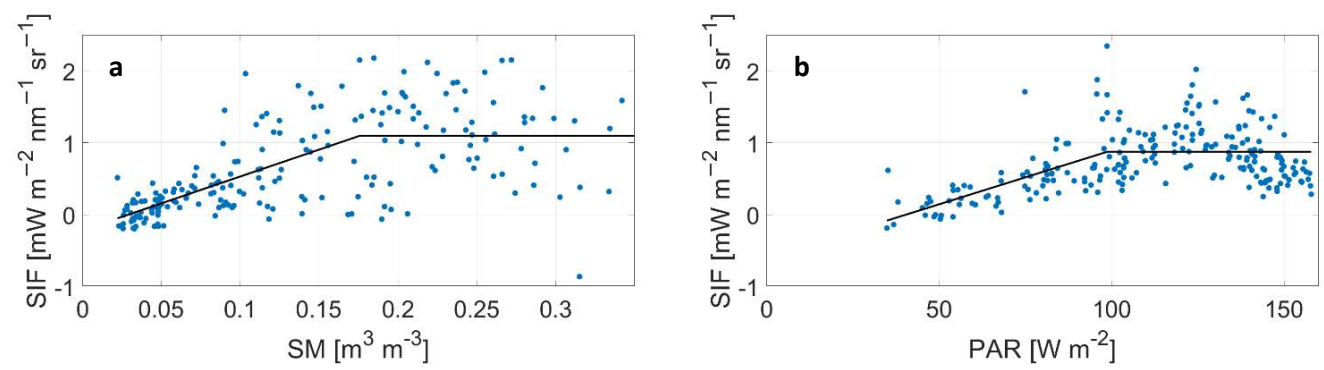

Figure 5: Example SIF relationships with water and light. Scatter plot of (a) sun-induced chlorophyll fluorescence (SIF,

$\left.\left[\mathrm{mW} \mathrm{m}^{-2} \mathrm{~nm}^{-1} \mathrm{sr}^{-1}\right]\right)$ and soil moisture (SM, $\left.\left[\mathrm{m}^{3} \mathrm{~m}^{-3}\right]\right)$ data and (b) SIF and photosynthetically active radiation (PAR, [W

$\left.\mathrm{m}^{-2}\right]$ ) data for the primary growing season and for a single $72 \times 72 \mathrm{~km}^{2}$ pixel located in (a) Sahel region (Mali) and (b) Spain (Segovia). Data are fitted with a two-regime model.

\section{Results and Discussion} criterion) among the three model types described above (linear, two-regime or zero-slope model) for each limitation (water and light).

\subsection{Water-limited regimes}

The spatial distribution of the selected model types, the corresponding model slopes, and the frequency distribution of model threshold for the SIF-SM relationship are shown in Fig. 6. Several regions with a two-regime water-limitation can be clearly identified, such as most of sub-Saharan Africa (except the Congo Basin), Southern Asia, Eastern Australia, Eastern Brazil, and Mexico. Few regions are identified as having no water-limitation meaning that while their growing season SIF-SM correlation is positive, it does not aid the fit in model estimation to have a non-zero slope. This likely means that the SIF-SM slope is positive, but near zero. Among the pixels showing a water limitation on photosynthesis, $73.5 \%$ were characterized by a two-regime behavior. Arid and semi-arid regions, with sparsely vegetated areas, show expected water limitation patterns.

Slope values are the highest (up to $10\left[\mathrm{~mW} \mathrm{~m}^{-2} \mathrm{~nm}^{-1} \mathrm{sr}^{-1}\right]$ per volumetric water content $\left[\mathrm{m}^{3} \mathrm{~m}^{-3}\right]$ ) in the Sahel region, Miombo woodlands south of the Congo Basin (Angola, Zambia, Mozambique), India, and Eastern Brazil. These regions correspond well to the tropical climate, sub-climate savannah, of the Köppen-Geiger climate classification 
285 (Beck et al., 2018). In these regions, a small increment of water in the soil corresponds to a large increase in vegetation productivity and therefore the expected 8-day mean fluorescence emission. The high slope values of the regression between SIF and SM in drylands is mainly due to the clear relationship between photosynthetic efficiency, and therefore also $\phi_{\mathrm{F}}$, and water availability. As a feedback of the increase in photosynthetic activity, the plant green biomass increases, leading to an increase in $\mathrm{PPAR}_{\mathrm{Chl}}$. The latter effects are especially determined by the water supply over drylands (Moreno-de las Heras et al., 2015). SIF observations allows to monitor the combined biomass and photosynthetic efficiency effect. Values of the model threshold are between 0 and $0.45 \mathrm{~m}^{3} \mathrm{~m}^{-3}$ with a median around 0.1-0.2 $\mathrm{m}^{3} \mathrm{~m}^{-3}$ (Fig. $6 \mathrm{c}$ and Fig. S3a for the spatial distribution). When the soil moisture state is above this threshold, SIF has minimal to no water limitation. It is worth noting that the threshold value might be harder to detect for regions with a low slope value. Furthermore, the SM thresholds are correlated (across space) with mean annual precipitation ( $\rho=0.25, P<0.01$, and $\rho=0.29, P<0.01$ when considering only regions below $1,000 \mathrm{~mm} \mathrm{yr}^{-1}$ ) as well as with soil texture $(\rho=0.32, P<0.01$ with clay fraction; $\rho=-0.37, P<0.01$ with sand fraction). 
https://doi.org/10.5194/bg-2022-25

Preprint. Discussion started: 31 January 2022

(c) Author(s) 2022. CC BY 4.0 License.

a

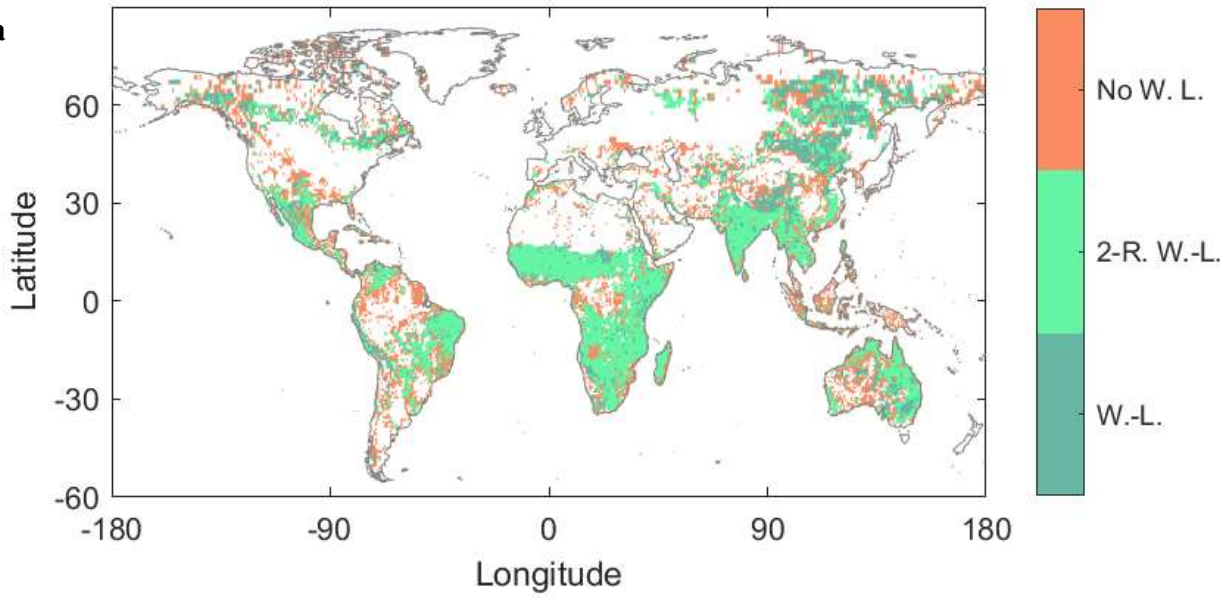

b

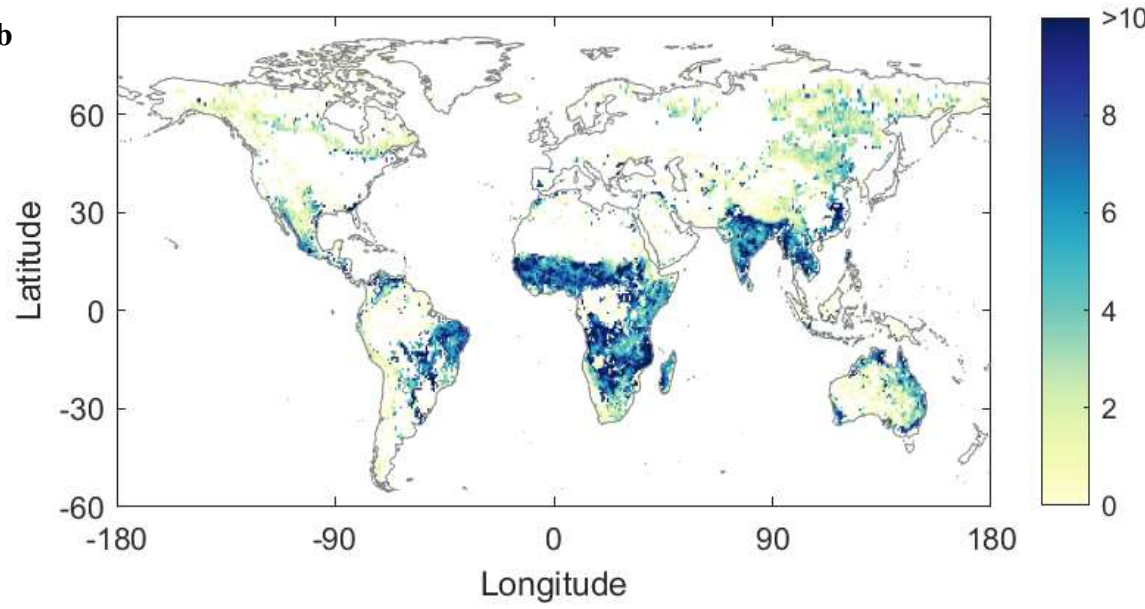




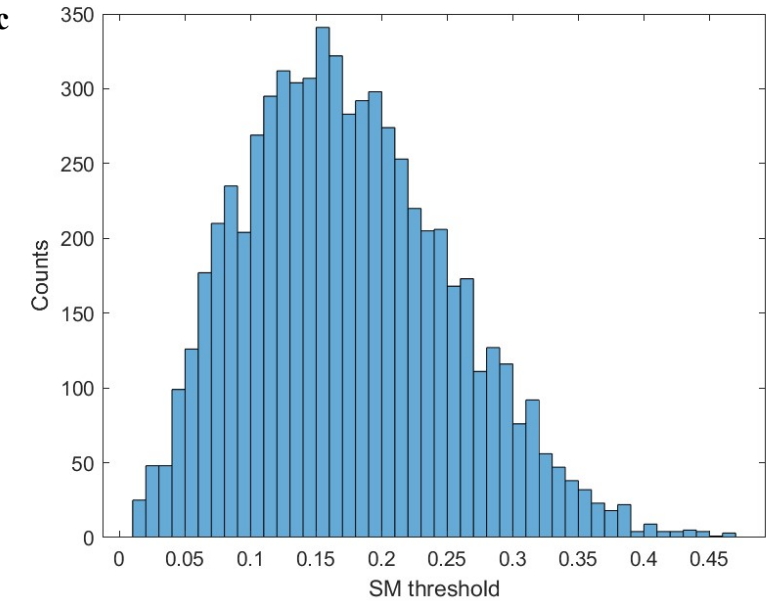

Figure 6: Estimated SIF-soil moisture relationship features. (a) Model type (W.-L.: Water-Limited; 2-R. W.-L.: TwoRegime Water-Limited; No W. L.: No Water Limitation), (b) model slope $\left[\mathrm{mW} \mathrm{m}^{-2} \mathrm{~nm}^{-1} \mathrm{sr}^{-1}\right]$ in the water limited regime, and (c) model threshold $\left[\mathrm{m}^{3} \mathrm{~m}^{-3}\right]$ for the SIF-SM relationship. White shading denotes areas where the SIF-SM correlation is not positive-i.e., where SIF is not increasing with SM-or areas where no collocated SIF, SM, and PAR records are available.

\subsection{Light-limited regimes}

The spatial distribution of the selected model types, the corresponding model slopes, and the frequency distribution of model threshold for the SIF-PAR relationship are shown in Fig. 7. In contrast to the SIF-SM relationship, a lightlimitation regime is observed in many parts of the northern hemisphere, mainly in Southern Canada, the Western U.S., the U.S. East coast, Western and Central Russia, the Balkans, and the Baltic region. Several regions are identified as having a break point between two-regimes of light (non-) limitation, such as Western Europe (France, Germany, Spain), Northern Russia, the U.S. Corn Belt, South-Eastern South America and South-Eastern Africa. Among the pixels showing a light limitation on photosynthesis, only $36.1 \%$ were characterized by a two-regime behavior. These regions of two-regime light limitation and threshold behavior is novel given that two-regime light influences on photosynthesis has not been observed or considered at large-scales previously.

Slope values are highest (up to $0.015\left[\mathrm{~mW} \mathrm{~m}^{-2} \mathrm{~nm}^{-1} \mathrm{sr}^{-1}\right]$ per $\left[\mathrm{W} \mathrm{m}^{-2}\right]$ ) in the Great Lakes regions of North America, most of Europe, Southern Russia, Northern Argentina, and Southern Brazil. These regions correspond well to the cold and temperate climates, sub-climate without dry season (hot or warm summer), of the Köppen-Geiger climate 

a large part of the SIF-PAR relationship over these regions. In these regions, a small increment of light will substantially increase the vegetation productivity and therefore the expected fluorescence emission. By contrast, in the high latitudes of the northern hemisphere, slope values are the lowest, probably due to low vegetation densities or the presence of boreal evergreen forests. Values of the estimated PAR threshold are between 0 and $140\left[\mathrm{~W} \mathrm{~m}^{-2}\right]$ with a maximum occurrence around 100-110 [W m $\left.{ }^{-2}\right]$ (Fig. 7C and Fig. S3b for the spatial distribution). When light availability is above this threshold, SIF has minimal to no light limitation. Such threshold behavior is theoretically expected based on the nonlinear relationship between incoming shortwave radiation and plant carbon fixation (Jones, 2014). The PAR thresholds are additionally correlated (across space) with mean annual precipitation $(\rho=0.31, P<$ 0.01 , and $\rho=0.39,<0.01$ when considering only regions below $\left.1,000 \mathrm{~mm} \mathrm{yr}^{-1}\right)$ and with soil texture $(\rho=0.28, P<$ 0.01 with clay fraction; $\rho=-0.06, P<0.01$ with sand fraction). We note that PAR may relate strongly with surface temperature at seasonal scales in the northern hemisphere and thus relationships here may include the influence of surface temperature (Buermann et al., 2018; Zhang et a., 2020a). For example, the high SIF slope in the northern hemisphere midlatitudes may be inflated because we do not partition temperature limitation, which requires future investigation.

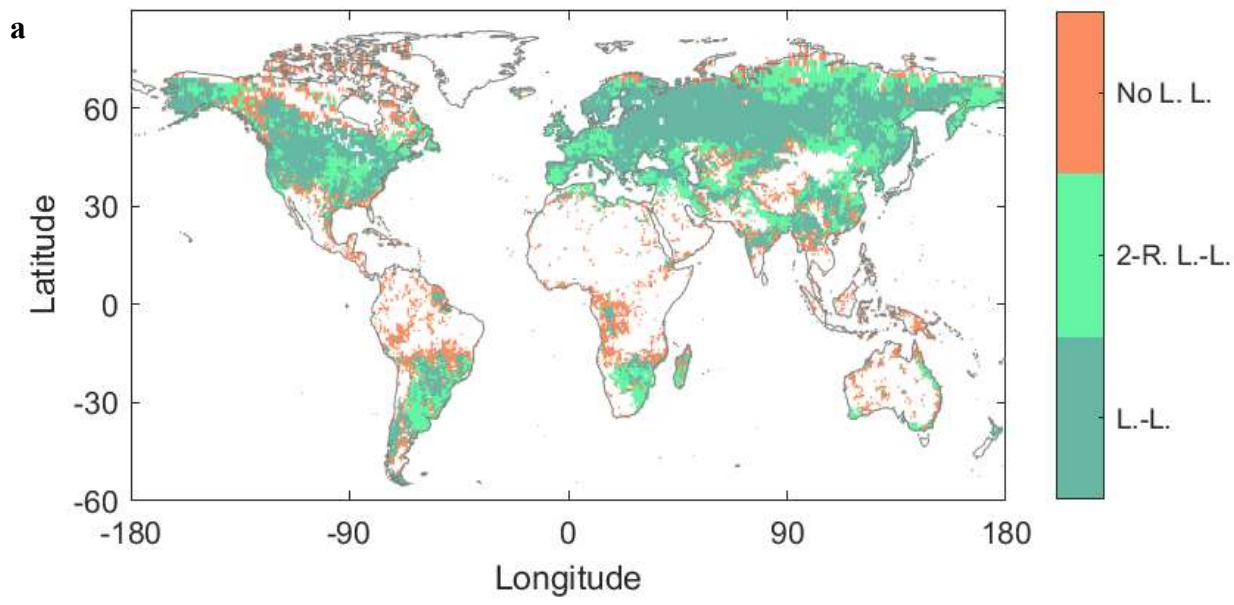


https://doi.org/10.5194/bg-2022-25

Preprint. Discussion started: 31 January 2022

(c) Author(s) 2022. CC BY 4.0 License.

b

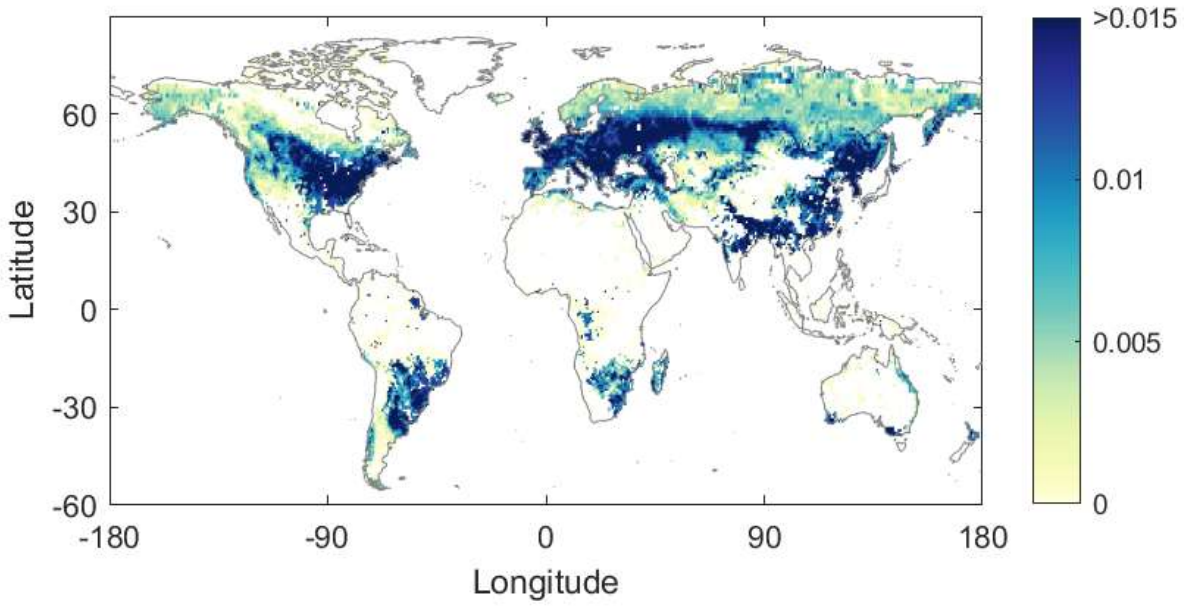

350

c

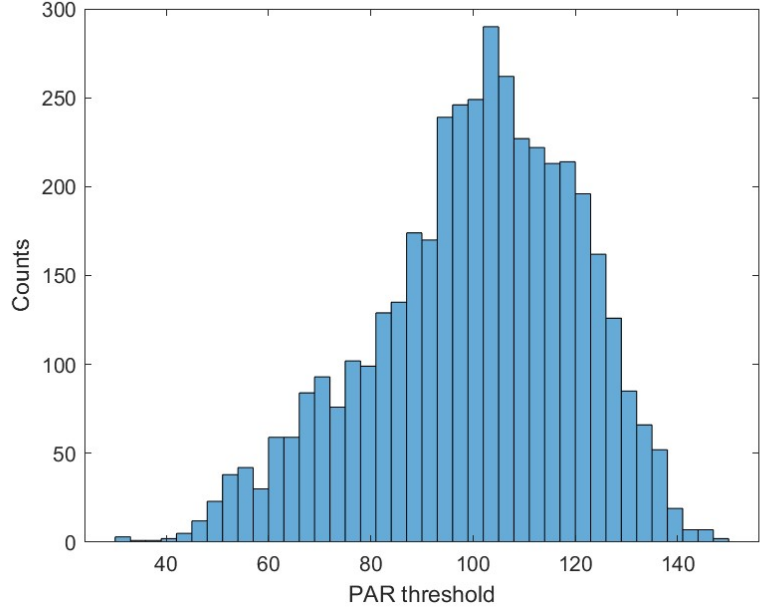

360

Figure 7: Estimated SIF-photosynthetically active radiation relationship features. Model type (L.-L.: Light-Limited; 2-R.

L.-L.: Two-Regime Light-Limited; No W. L.: No Light Limitation), model slope $\left[10^{-3} \mathrm{~nm}^{-1} \mathrm{sr}^{-1}\right]$ in the light-limited regime and model threshold $\left[\mathrm{W} \mathrm{m}^{-2}\right]$ for the SIF-PAR relationship. Same format as Fig. 6. 

slopes corresponding to sloped part of the two-regime model and the one-regime linear model). Locations with peak slopes occur in the wetter environments such as in India, Southeastern Asia, Angola, and Mozambique. These larger slopes are likely related to the degree to which vegetation responds to mean moisture and individual storms, given the weekly timescales of this analysis (Feldman et al., 2018; Maurer et al., 2020). $1,000 \mathrm{~mm} \mathrm{yr}^{-1}$. The increasing sensitivities may similarly be an adaptation of the vegetation to utilize light availability, given that moisture is typically less limited in these regions.
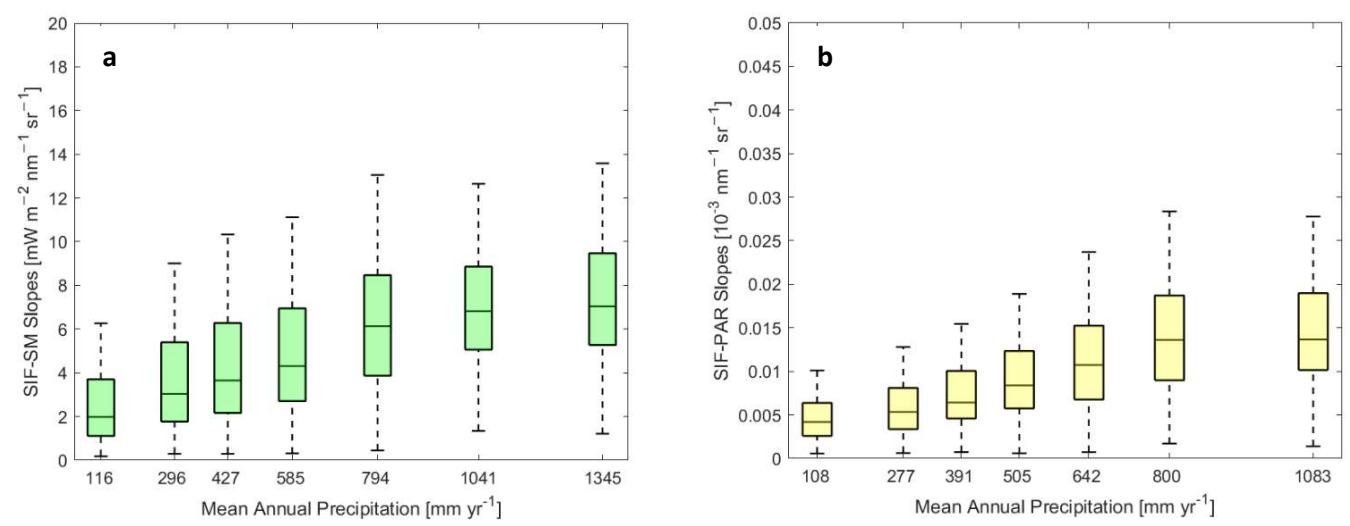

Figure 8: (a) SIF-SM slopes $\left[\mathrm{mW} \mathrm{m} \mathrm{m}^{-2} \mathrm{~nm}^{-1} \mathrm{sr}^{-1}\right]$ and (b) SIF-PAR slopes $\left[10^{-3} \mathrm{~nm}^{-1} \mathrm{sr}^{-1}\right]$ binned as a function of mean annual precipitation $\left[\mathrm{mm} \mathrm{yr}^{-1}\right]$ obtained from the Global Precipitation Measurement (GPM) satellite mission. Slopes value corresponds to sloped part of the two-regime model and the linear model. Each boxplot bin includes the same number of data points (1102 and 1459 data points for the boxplots with the SIF-SM slopes and the SIF-PAR slopes, respectively). Box edges are the 25th and 75th percentiles of the distribution bounding the median (red line), and whiskers extend to extrema (maximum and minimum). Both the median SIF-SM slope and the median SIF-PAR slope increase with increasing mean annual precipitation. 
https://doi.org/10.5194/bg-2022-25

Preprint. Discussion started: 31 January 2022

(c) Author(s) 2022. CC BY 4.0 License.

\subsection{Robustness, Limitations, and Future Work}

These results are on a six-month period for the growing season. We did not find seasonality and choice of season length impact the analysis in major ways because similar spatial patterns and qualitative results occur for a range of growing lengths (not shown).

We emphasize that we use the two-regime model given known nonlinear relationships that drive environmental influence on plant function (Jarvis, 1976). As such, studies that do not acknowledge the different regimes and assume linear SIF relationships with the environment would bias estimations of SIF-SM or SIF-PAR relationships. We therefore emphasize first detecting a breakpoint threshold before estimating slopes.

We aimed to only detect and observe the emerging relationships in nature on how photosynthesis is limited by water and light. The procedure was purposefully naïve and required few assumptions, allowing the observations alone to drive the results. This is a first step in the process of using detection procedures that include interactive effects of water and light with other variables. One can also obtain more mechanistic understanding of physiological behavior by estimating parameters, such as from Eq. (1), from the observed behavior in Figs. 6 and 7. However, these future approaches require more assumptions, which have the added challenge of detecting natural emerging behavior without biasing the results with restrictive assumptions.

The observation-only approach is chosen to best identify the naturally occurring and emerging plant function response to the environment. Such a study informs others that use model or reanalysis frameworks that have built-in assumptions that may confound the results. Nevertheless, the use of PAR from reanalysis here should be updated in the future with globally available shortwave radiation observations. Ultimately, we expect that MERRA-2 PAR is not largely influenced by built-in interactions with land surface behavior given that it is driven mostly by the atmospheric model scheme and assimilation of soundings.

Our analysis may not capture the range of limitations on plant function. For instance, no water- and no light-limitation can be seen in the same region (such as tropical forests) where other bio-climatic factors (such as nutrient limitation) could influence plant growth. Predominance of water versus light limiting regime might also shift over the growing season and between years, particularly in transitional climate regions (Seneviratne et al., 2010). While our analysis is not exhaustive in evaluating all possible factors (e.g., vapor pressure deficit, air temperature, nutrients) and their interactions, it highlights that vegetation function exhibits widespread, nonlinear dependencies on bio-climatic factors that are highly spatially variable. Given that we show vegetation existing in limited and non-limiting states depending 

landscape-scale photosynthesis.

Note that we repeated results with GOME-2 and OCO-2 SIF, which resulted in similar spatial patterns (not shown). However, TROPOMI was used given that its higher spatiotemporal coverage was essential for the regime classification here.

\section{Summary and Conclusion}

In this study, we map observational evidence for seasonal water-limitation and light-limitation in plant function at the ecosystem scale. We analyzed data from three different satellite sensors, namely solar-induced chlorophyll fluorescence from TROPOMI, surface soil moisture from SMAP, and leaf area index from MODIS. In this purely observationally driven study, the combination of the three data streams allowed us to test a set of hypotheses on the types and extent of bio-climatic regions that should be classified as under each seasonal water- or light limitation.

To detect where nonlinear controls of water and light on photosynthesis occur, three distinct models were tested representing three scenarios for each limitation (water and light). The first model is the linear model representing the water- or light-limited regime. The second model is the nonlinear two-regime model representing the situation where the rate limitation ceases above a certain threshold of soil moisture or photosynthetically active radiation. The conditions to select this model are conservative and thus we exhibit confidence in the detection of nonlinear controls when this model is selected. The third model is the zero-slope model for the no water or no light limitation regime. The main results show that soil moisture limits on SIF are found primarily in drier environments while PAR limitations are found in intermediately wet regions. Nonlinear two-regime behavior is observed in $73.6 \%$ of the cases for water limitation on photosynthesis, while two-regime detection is much lower at $36.2 \%$ for light limitation on photosynthesis. Nevertheless, these nonlinear relationships are theoretically expected and widely observed across the globe for light limitation for the first time here. SIF sensitivity to PAR strongly increases along moisture gradients, reflecting mesic vegetation's adaptation to making rapid usage of incoming light availability on the weekly timescales investigated here. The transition point detected between the two regimes is connected to soil type and mean annual precipitation for both the SIF-soil moisture and SIF-PAR relationships. These thresholds have therefore an explicit relation to properties of the landscape, although they may also be related to finer details of the vegetation and soil interactions not resolved by the spatial scales here. Future work can account for interactions between more variables and more explicit 
characterization of the nonlinear relationships in each pixel. Successful, systematic detection of nonlinear controls of individual environmental variables on photosynthesis with the statistical relationships is a first step here.

Our study is unique in detecting the nonlinear relationships between plant function and water and light, major controls derived parameters, and can therefore serve as a benchmark to directly assess the terrestrial gross primary production outputs of

\section{Acknowledgments}

The authors want to acknowledge the Massachusetts Institute of Technology (MIT) for supporting this research with the MIT-Belgium Seed Fund "Early Detection of Plant Water Stress Using Remote Sensing".

\section{References}

Akbar R., Short Gianotti D. J., McColl K. A., Haghighi E., Salvucci G. D., \& Entekhabi D. 2018a. Estimation of landscape soil water losses from satellite observations of soil moisture. Journal of Hydrometeorology, 19, 871-889.

Akbar R., Short Gianotti D. S., McColl K. A., Haghighi E., Salvucci G. D., and Entekhabi D. 2018b. Hydrological storage length scales represented by remote sensing estimates of soil moisture and precipitation. Water Resources Research, 54, 1476-1492.

Alemohammad S.H., Fang B., Konings A.G., Aires F., Green J.K., Kolassa J., Miralles D., Prigent C., Gentine P. 2017. Water, Energy, and Carbon with Artificial Neural Networks (WECANN): a statistically based estimate of global surface turbulent fluxes and gross primary productivity using solar-induced fluorescence. Biogeosciences, 14, 41014124.

Ahlström A., Raupach M. R., Schurgers G., Smith B., Arneth A., Jung M., Reichstein M., Canadell J. G., Friedlingstein P., Jain A. K., Kato E., Poulter B., Sitch S., Stocker B. D., Viovy N., Wang Y. P., Wiltshire A., Zaehle S., Zeng N. 2015. The dominant role of semi-arid ecosystems in the trend and variability of the land CO2 sink. Science, $348,895-$ 899. 

Moisture. Geophys. Res. Lett., e2020GL087077.

Beck, H., Zimmermann, N., McVicar, T. et al. 2018. Present and future Köppen-Geiger climate classification maps at 1-km resolution. Scientific Data, 5, 180214.

Beer C., Reichstein M., Tomelleri E., Ciais P., Jung M., Carvalhais N., Rödenbeck C., Arain M.A., Baldocchi D.,

Roupsard O., Veenendaal E., Viovy N., Williams C., Woodward F.I., Papale D. 2010. Terrestrial gross carbon dioxide uptake: Global distribution and covariation with climate. Science, 329, 834-838.

Buermann W., Forkel M., O’Sullivan M. et al. 2018. Widespread seasonal compensation effects of spring warming on northern plant productivity. Nature, 562, 110-114.

Bush E.R., Bunnefeld N., Dimoto E., Dikangadissi J.-T., Jeffery K., Tutin C., White L., Abernethy K.A. 2018. Towards effective monitoring of tropical phenology: maximizing returns and reducing uncertainty in long-term studies. Biotropica, 50, 455-464.

Entekhabi D. et al. 2010. The Soil Moisture Active Passive (SMAP) mission. Proc. IEEE, 98(5), 704-716.

Feldman, A. F., A. G. Konings, M. Piles, D. Entekhabi. 2021). The Multi-Temporal Dual Channel Algorithm (MT-

Feldman A.F., Short Gianotti D.J., Trigo I.F., Salvucci G.D., Entekhabi D. 2019. Satellite-Based Assessment of Land Surface Energy Partitioning-Soil Moisture Relationships and Effects of Confounding Variables. Water Resources Research, 55 (12), 10657-10677.

Feldman A.F., Short Gianotti D.J., Konings A.G., McColl K.A., Akbar R., Salvucci G.D., Entekhabi D. 2018. Moisture

Fisher R.A., Koven C.D., Anderegg W.R.L., Christoffersen B.O., Dietze M.C., Farrior C.E., Holm J.A., Hurtt G.C., Knox R.G., Lawrence P.J., Lichstein J.W., Longo M., Matheny A.M., Medvigy D., Muller-Landau H.C., Powell T.L., Serbin S.P., Sato H., Shuman J.K., Smith B., Trugman A.T., Viskari T., Verbeeck H., Weng E., Xu C., Xu X., Zhang 
T., Moorcroft P.R. 2018. Vegetation demographics in Earth System Models: A review of progress and priorities. Glob.

Flanagan L.B., Ehleringer J.R., Marshall J.D. 1992. Differential uptake of summer precipitation among co-occurring trees and shrubs in a pinyon-juniper woodland. Plant, Cell Environ., 15, 831-836.

Gentine P., Green J.K., Guérin M., Humphrey V., Seneviratne S.I., Zhang Y., Zhou S. 2019. Coupling between the terrestrial carbon and water cycles-a review. Environ. Res. Lett., 14, 083003.

Global Modeling and Assimilation Office (GMAO). 2015. MERRA-2 tavg1_2d_lfo_Nx: 2d,1-Hourly,TimeAveraged,Single-Level,Assimilation,Land Surface Forcings V5.12.4, Greenbelt, MD, USA, Goddard Earth Sciences Data and Information Services Center (GES DISC), Accessed: April 15, 2021, 10.5067/L0T5GEG1NYFA

Gonsamo A., Chen J.M., He L., Sun Y., Rogers C., Liu J. 2019. Exploring SMAP and OCO-2 observations to monitor soil moisture control on photosynthetic activity of global drylands and croplands, Remote Sensing of Environment, 232,111314

Green J., Konings A., Alemohammad S. et al. 2017. Regionally strong feedbacks between the atmosphere and terrestrial biosphere. Nature Geoscience, 10, 410-414.

He L., Magney T., Dutta D., Yin Y., Köhler P., Grossmann K., et al. 2020. From the ground to space: Using solarinduced chlorophyll fluorescence to estimate crop productivity. Geophysical Research Letters, 47, e2020GL087474. Evol, 2, 1897-1905.

Huffman G., Stocker E.F., Bolvin D.T., Nelkin E.J., Tan, J. 2019. GPM IMERG Final Precipitation L3 Half Hourly 0.1 degree x 0.1 degree V06, Greenbelt, MD, Goddard Earth Sciences Data and Information Services Center (GES DISC), Accessed: 03.01.20.

Jarvis P.G. 1976. Interpretation of variations in leaf water potential and stomatal conductance found in canopies in field. Philos T Roy Soc B, 273 (927), 593-610. 
Jasechko S., Sharp Z.D., Gibson J.J., Birks S.J., Yi Y., Fawcett P.J. 2013. Terrestrial water fluxes dominated by transpiration. Nature 496, 347-350.

Joiner J., Yoshida Y., Vasilkov A., Schaefer K., Jung M., Guanter L., Zhang Y., Garrity S., Middleton E.M., Huemmrich K.F., Gu L., Marchesini L.B. 2014. The seasonal cycle of satellite chlorophyll fluorescence observations and its relationship to vegetation phenology and ecosystem atmosphere carbon exchange. Remote Sensing of Environment, 152, 375-391.

Jonard F., De Cannière S., Brüggemann N., Gentine P., Short Gianotti D. J., Lobet G., Miralles D. J., Montzka C., Pagán B. R., Rascher U., and Vereecken H. 2020. Value of chlorophyll fluorescence for quantifying hydrological states and fluxes: Current status and challenges. Agricultural and Forest Meteorology, 291, 108088.

Jones, H.G., 2014. Plants and Microclimate: A quantitative approach to environmental plant physiology, 3rd ed. Cambridge University Press, Cambridge, UK.

Kerr Y. H. et al. 2010. The SMOS mission: New tool for monitoring key elements of the global water cycle. Proc. IEEE, 98(5), 666-687.

Kim S., 2013. Ancillary Data Report: Landcover Classification. Jet Propuls. Lab. Calif. Inst. Technol., JPL D-53057.

Köhler P, Frankenberg C., Magney T. S., Guanter L., Joiner J., and Landgraf J. 2018. Global retrievals of solar-induced chlorophyll fluorescence with TROPOMI: first results and intersensor comparison to OCO-2. Geophysical Research Letters, 45 (19), 10456-10463.

Konings A. G. et al. 2016. Vegetation optical depth and scattering albedo retrieval using time series of dual-polarized L-band radiometer observations. Remote Sensing of Environment, 172, 178-189.

Liang X.-Z., Wu Y., Chambers R.G., Schmoldt D.L., Gao W., Liu C., Liu Y.-A., Sun C., Kennedy J.A. 2017. Determining climate effects on US total agricultural productivity. Proc. Natl. Acad. Sci. 114, E2285-E2292.

Liu L., Gudmundsson L., Hauser M., Qin D., Li S., Seneviratne S.I. 2020. Soil moisture dominates dryness stress on ecosystem production globally. Nat Communication, 11, 4892. 
Lu X.L., Liu Z.Q., An S.Q., Miralles D.G., Maes W.H., Liu Y.L., Tang J.W. 2018. Potential of solar-induced chlorophyll fluorescence to estimate transpiration in a temperate forest. Agricultural and Forest Meteorology, 252, 75. Madani N., Kimball J.S., Jones L.A., Parazoo N.C., Guan K. 2017. Global Analysis of Bioclimatic Controls on Ecosystem Productivity Using Satellite Observations of Solar-Induced Chlorophyll Fluorescence. Remote Sensing, 9, 530.

Maes W.H., Pagán B.R., Martens B., Gentine P., Guanter L., Steppe K., Verhoest N.E.C., Dorigo W., Li X., Xiao,J., Miralles D.G. 2020. Sun-induced fluorescence closely linked to ecosystem transpiration as evidenced by satellite data and radiative transfer models. Remote Sensing of Environment, 249.

Maurer G.E., Hallmark A.J., Brown R.F., Sala O.E., Collins S.L. 2020. Sensitivity of primary production to precipitation across the United States. Ecol. Lett., 23, 527-536.

McCarty W., Coy L., Gelaro R., Huang A., Merkova D., Smith E. B., Sienkiewicz M., Wargan K. 2016. MERRA-2 input observations: Summary and initial assessment. Technical Report Series on Global Modeling and Data Assimilation, 46, NASA Tech. Rep. NASA/TM-2016-104606, 61 pp. [Available online at https://gmao.gsfc.nasa.gov/pubs/docs/McCarty885.pdf.]

Meinzer F.C., Luis J., Goldstein G., Holbrook N.M., Cavelier J., Wright S.J. 1999. Partitioning of soil water among canopy trees in a seasonally dry tropical forest. Oecologia, 293-301.

Miguez-Macho G., Fan Y. 2021. Spatiotemporal origin of soil water taken up by vegetation. Nature, 598, 624-628.

Monteith J.L. 1972. Solar Radiation and Productivity in Tropical Ecosystems. Journal of Applied Ecology, 9 (3), $747-$ 766.

Morellato L.P.C., Abernethy K., Mendoza I. 2018. Rethinking tropical phenology: insights from long-term monitoring and novel analytical methods. Biotropica, 50: 371-373.

Moreno-de las Heras M., Díaz-Sierra R., Turnbull L., Wainwright J. 2015. Assessing vegetation structure and ANPP dynamics in a grassland-shrubland Chihuahuan ecotone using NDVI-rainfall relationships. Biogeosciences, 12, 29072925 
Moulin S., Kergoat L., Viovy N., Dedieu, G. 1997. Global-Scale Assessment of Vegetation Phenology Using NOAA/AVHRR Satellite Measurements. Journal of Climate, 10(6), 1154-1170.

Myneni R., Knyazikhin Y., Park T. 2015. MCD15A2H MODIS/Terra+Aqua Leaf Area Index/FPAR 8-day L4 Global 500m SIN Grid V006. NASA EOSDIS Land Processes DAAC. http://doi.org/10.5067/MODIS/MCD15A2H.006

Nemani R.R., Keeling C.D., Hashimoto H., Jolly W.M., Piper S.C., Tucker C.J., Myneni R.B., Running S.W. 2003. Climate-driven increases in global terrestrial net primary production from 1982 to 1999 . Science, 300(5625), 15601563.

Njoku E.G., Entekhabi, D. 1996. Passive microwave remote sensing of soil moisture. J. Hydrol., 184, 101-129.

Pagan B.R., Maes W.H., Gentine P., Martens B., Miralles D.G. 2019. Exploring the Potential of Satellite Solar-Induced Fluorescence to Constrain Global Transpiration Estimates. Remote Sensing, 11.

Peano D., Materia S., Collalti A., Alessandri A., Anav A., Bombelli A., Gualdi, S. 2019. Global variability of simulated and observed vegetation growing season. Journal of Geophysical Research: Biogeosciences, 124, 3569-3587.

Seneviratne S. I., Corti T., Davin E. L., Hirschi M., Jaeger E. B., Lehner I., Orlowsky B., Teuling A. J. 2010. Investigating soil moisture-climate interactions in a changing climate: A review. Earth-Sci. Rev.99, 125-161.

Shan N., Ju W.M., Migliavacca M., Martini D., Guanter L., Chen J.M., Goulas Y., Zhang Y.G. 2019. Modeling canopy conductance and transpiration from solar-induced chlorophyll fluorescence. Agricultural and Forest Meteorology, 268, 189-201.

Short Gianotti D.J., Rigden A.J., Salvucci G.D., Entekhabi D. 2019a. Satellite and Station Observations Demonstrate Water Availability's Effect on Continental-Scale Evaporative and Photosynthetic Land Surface Dynamics. Water Resources Research 55, 540-554.

Short Gianotti D. J., Salvucci G. D., Akbar R., McColl K. A., Cuenca R., Entekhabi D. 2019b. Landscape water storage

Research, 55, 9111- 9132 . 
Teubner I.E., Forkel M., Jung M., Liu Y.Y., Miralles D.G., Parinussa R., van der Schalie R., Vreugdenhil M., Schwalm C.R., Tramontana G., Camps-Valls G., Dorigo W.A. 2018. Assessing the relationship between microwave vegetation optical depth and gross primary production. Int. J. Appl. Earth Obs. Geoinf. 65, 79-91. New Phytologist.

Wang X., Dannenberg M. P., Yan D., Jones M. O., Kimball J. S., Moore D. J. P., et al. 2020. Globally consistent patterns of asynchrony in vegetation phenology derived from optical, microwave, and fluorescence satellite data. Journal of Geophysical Research: Biogeosciences, 125, e2020JG005732. dynamics mediate the response of SIF to water stress in a potato crop. Remote Sensing of Environment, 263, 112555.

Zhang X., Friedl M. A., Schaaf, C. B. 2006. Global vegetation phenology from Moderate Resolution Imaging Spectroradiometer (MODIS): Evaluation of global patterns and comparison with in situ measurements. J. Geophys. Res., 111, G04017. relationship between sun-induced chlorophyll fluorescence and gross primary production for remote sensing applications. Remote Sensing of Environment, 187, 145-155.

Zhang Y., Commane R., Zhou S. et al. 2020a. Light limitation regulates the response of autumn terrestrial carbon uptake to warming. Nat. Clim. Chang., 10, 739-743. 